Military Technical College Kobry El-Kobbah, Cairo, Egypt

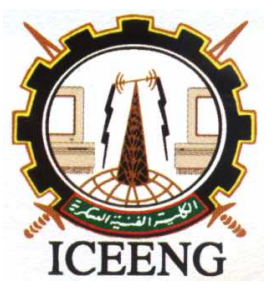

\author{
$6^{\text {th }}$ International Conference \\ on Electrical Engineering \\ ICEENG 2008
}

\title{
Navigation and perception in mobile robotics technical fuzzy approach
}

$$
\text { By }
$$

Kheira Abdelmoudjib*

\author{
Gerard Bourdon**
}

\section{Abstract:}

There is a net development of devices which at various degrees can be qualified as robots or arm manipulators; the extent of their possibilities, and the complexity of the movements they can make; on the one hand, and their ability to respond automatically to the externals information's in other hand; make the problem of command-control and perception; becomes an important subject, of study and research in robotics.

The purpose of this article is to present the diverse possible applications of sensors with digital-fuzzy interface (smart sensor) s.s. fuzzy sensors. Concepts will be presented as well as the development of analytical model and qualitative model of the sensor, in the case of mobile robot navigating in the unknown and dynamic environment

The use of these concepts is then illustrated by simulation. The simulation results are presented and commented

\section{Keywords:}

Mobile robots; fuzzy controller; intelligent sensor; analytical model; qualitative model.

* Higher School of Technical Teaching and Engineering, Oran, Algeria

** Vitry High Technology Institute, Paris 12 University, France 


\section{Introduction:}

It is noted in industry a clear development of devices that can be defined as robots or manipulating arms at various degrees. The extent of their possibilities, at one hand the variety and complexity of the movements they can make; and on the other hand their ability to respond automatically to external information makes that the issue of command control and perception becomes an important topic of study and research in robotics.

In order for a robot to adapt itself efficiently to its environment, it would be interesting to develop its modelling. The calculator possesses a model of the mechanical articulated system, the model of the environment, the data on tasks to be performed and a number of computational resources (strategies and computing) using exteroceptive information (state of the environment), which are obtained from sensors. The robot can grasp its environment and adapt itself (Detection of obstacles, controlling position, coercive measures... etc). There are many sensors used in mobile robotics. We focus on ultrasonic sensors because of their range, of the order of one to two meters. They are best suited to the measurement of distance and positioning; in addition they are relatively less encumbering, compact and inexpensive.

\section{Sensor; interaction with the environment:}

The measurements are often done using analog sensors usually consisting of a transducer, a conditioning device and a transmitter; the information exchanged between the sensor and controller is in analogue form. Thus the controller integrates A/D converters for the measurements and D/A converters for commands. The evolution of technology, particularly in the field of microprocessors, has led to use these components in the sensors. This innovation was simply to introduce these new sensors as intelligent. In [8], the author proposes a new vision of the sensor in its environment. It is presented as a system that can be defined as a set of subsystems. The basic systems are transducers and actuators that have a physical interface with the outside world [1], [2].

\section{Approach on the smart sensor concept:}

A description in terms of functionality, derived from the white book [7], sets out the broad lines of the concept. A smart sensor must, above all, make a valid measure. This is then transmitted to the user, who must have previously set the smart sensor - which highlights the functionality measure, configuration and communication [5], [6]. 


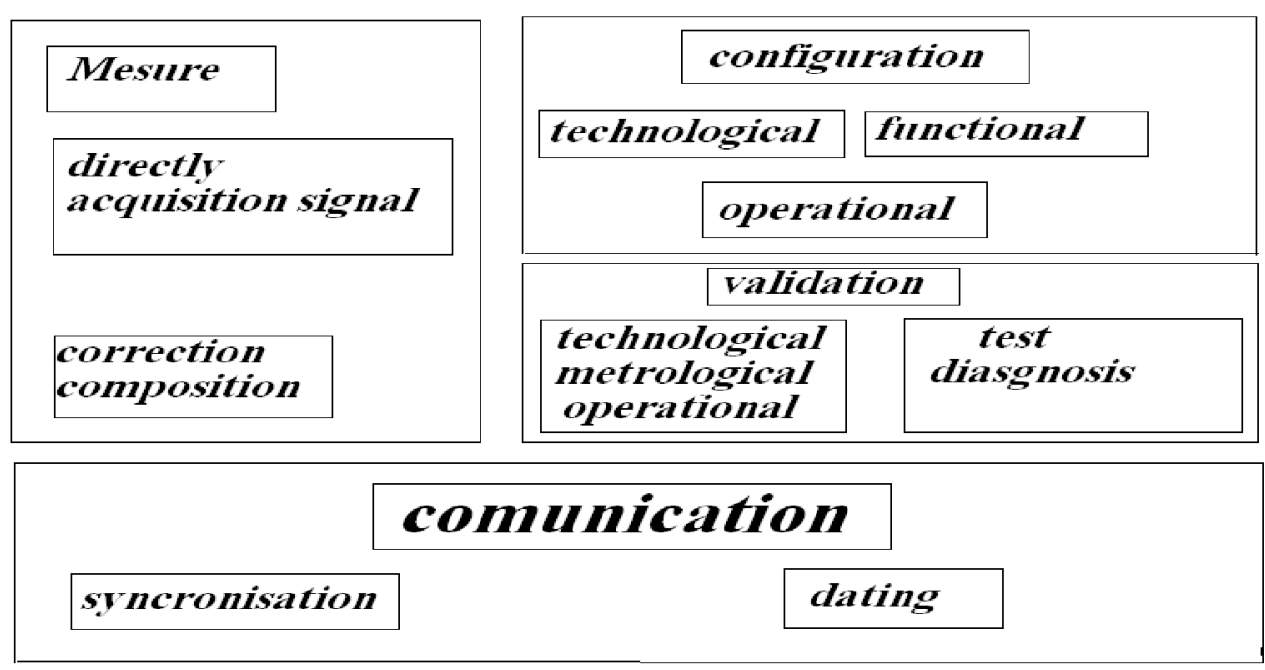

Figure (1): Smart sensors functionalities

\subsection{Measurement functionality:}

A smart sensor must before all carry out a validated measurement: the functionality measurement integrates the aspects of metrology and signal processing related to the sensor as well as to the exteroceptive physical variables. It is necessary to add the variables of self-checking, to which are associated the technological measurements that characterize the state of the sensor at one time $t$, the time which ensures a coherent dating of information, the models which contribute at various levels of validation of a database. It is interesting to note that all these sizes can be classified in:

- Local variables characterizing the physical environment of the smart sensor for example primary measurement: ambient temperature.

- Distant variables characterizing the system environment of the smart sensor for example clock system, network occupancy rate, and also any information emitted by any other sensor. All these variables contribute to obtaining a measurement.

\subsection{Validation functionality}

Functional measurement must be validated by the taking into account of technological measurements which characterize the correct operation of the smart sensor, so much in term of technology such as for example, measurement of the supply voltage, integrity of the chain of acquisition, checking of the good unfolding of an algorithm; that in term of methodology it is a question of testing the coherence of measurement compared to models such as : variation in the measurement extent ; detection of aberrant measurements in a time series ...

\subsection{Configuration functionality:}

The functionality configuration includes

- A technological configuration resulting from a whole of actions and their validations aiming at integrating the sensor in its physical environment; a functional configuration aiming at returning the sensor measuring and communicating

- An operational configuration aiming at dedicating the sensor to the application 
The functional and operational configurations initial can be modified on the initiative of the operator.

\subsection{Functionality communication:}

The functionality communication ensures the exchange of information between the sensor and its environment. It must decode and interpret the orders and messages which arrive at the sensor and, consequently to start the adequate actions. It also has in charge the setting of information to transmit from the smart sensor towards the external world.

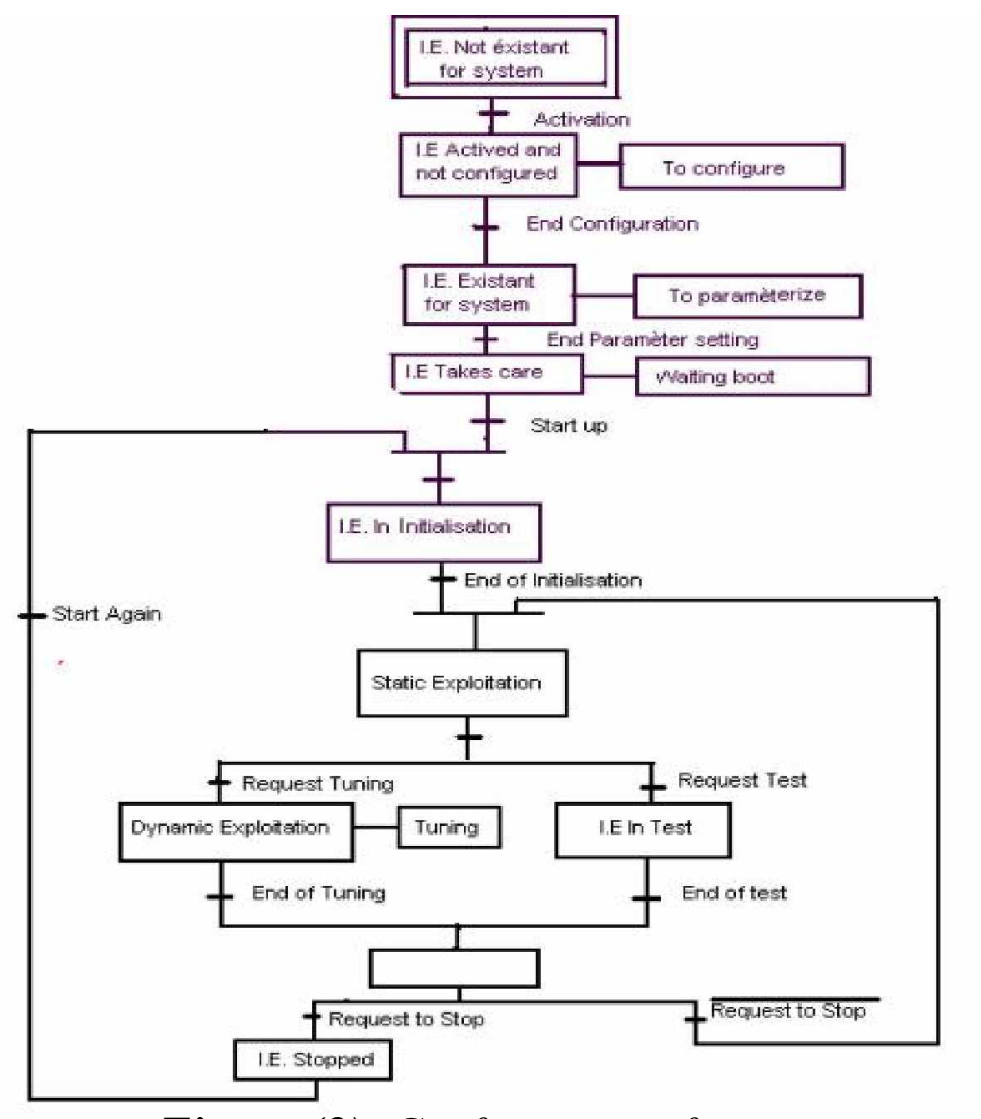

Figure (2): Grafcet state of a smart sensor

\section{Fuzzy Control:}

The fuzzy set theory was introduced in 1965 by ZADEH $[9,10]$, it allows to reason on knowledge which can be at the same time fuzzy (badly described) and dubious whose validity is subjected to a fuzzy control is a method of adjustment which tolerates a weak knowledge of the process, it finds its efficiency in the badly defined and complex processes which can be controlled by a human operator[3], specialized, without knowledge of their basic dynamics. The structure of a fuzzy controller is made of four parts.

\section{1 Database and rule:}

This block contains information concerning the applicability and the operation of the system in the fuzzy controller, the dynamic behaviour of the systems is described by linguistic rules of the form $<<$ if (checked conditions) then (consequences) $>$, generally 
deduced from knowledge by an expert of the system. This coding is mostly used because of the causality that it expresses.

\subsection{Fuzzification:}

In this part an actual value of a state variable is transformed into a variable compatible with the representation of the sets which one will have chosen. The phase of fuzzification consists in making a partition of the field of definition of the entries in fuzzy intervals. This partition is used then for the linguistic description of the relations between the entries and outputs.

\subsection{Fuzzy inference:}

In this part one determines the degree of validity of the rules brought into play starting from the state variable fuzzified; and one deduces a fuzzy conclusion.

\subsection{Défuzzification:}

The fuzzy conclusion is translated into likely no fuzzy ordering of controller suitably the process.

\section{Modelling [4]:}

In its work of these of doctorate mister Bourdon [4] study ; privileges the advance of the robot systematically. Any obstacle being located at the back the robot is being regarded as moving away relative to the robot and does not present any more a danger of collision. The obstacles are not reconstituted in the local plan of the robot because it does not know their geometries, for the robot these are segments whose configuration is approximate. It is characterized by its orientation and its position in the relative reference mark of the robot. In addition a mobile obstacle will be regarded as static at the moment $\mathrm{T}$ in the reference mark of the robot, the tactics of displacement will not be different, because the dynamics of the scene is being represented between two moments of sampling.

In addition for the control of the position of the plane it is only a question of detecting or not the presence of an object; relevant information is the distance. He chose the ultrasonic sensors at low cost and providing information of distance to the price of a simple treatment, which is significant in the order real time; the analysis of the data is done according to the three sides of the robot (front, left, right). The calculation of the distance compared to the first obstacle met by the ultrasonic wave in a given direction (principal direction of the beam is carried out by measurement of the time of flight of the emitted wave); interval of time passing between the beginning of the emission and the reception of the first echo.

5.1 Analytical model: controller takagi-sugeno the general

form of the rule is written:

If ( $X$ is $L_{X I}$ and is $\left.L y_{j}\right)$, then $U=f_{i j}(x . y)$

Where $\mathrm{f}_{\mathrm{ij}}$ is an analytical function of entries $\mathrm{x}$ and $\mathrm{y}$ of the controller. A particular case of rules of takagi-sugeno is that for which the functions $f_{i j}$ are constant. The preceding rule becomes: 
$R_{I J}$ : if ( $x$ is $L x_{i}$ and $y$ is $\left.L y_{j}\right)$, then $U=S_{i j}$

Where $S_{i j}$ is a fuzzy singleton corresponding to the Rij rule. Method of inference being method of individual inference, each rule being treated individually. The treatment can be described by 3 stages :

1. The calculation of membership of the entry to the vague sets which make the antecedent of the rule (fuzzification)

2. The weighting of the whole of exit describing the rule consequent by the weight of this rule.

3. The balanced values of the exits are aggregate to give the total value of exit.

If one takes again the Rij rule the degrees of membership of the entries $\mathrm{x}_{0}, \mathrm{y}_{0}$ to the fuzzy values $\operatorname{Lx}_{0}, \operatorname{Ly}_{0}$ noted : $\mu \operatorname{Lx}_{\mathrm{i}}\left(\mathrm{x}_{0}\right) ; \mu \operatorname{Ly}_{\mathrm{j}}\left(\mathrm{y}_{0}\right)$.

The weight or rate of excitation of the rule is then

$$
\sigma_{\mathrm{ij}}=\mu \operatorname{Lx}_{\mathrm{i}}\left(\mathrm{x}_{0}\right) \Lambda \mu \operatorname{Ly}_{\mathrm{j}}\left(\mathrm{y}_{0}\right)
$$

The individual inference gives for each rule the fuzzy exit:

$$
\mu \mathrm{U}_{\mathrm{ij}}=\sigma_{\mathrm{ij}} \cdot \mu_{\mathrm{ij}}(\mathrm{U})
$$

$\mathrm{U}$ being composed of let us singletons we have:

$$
\mu U_{i j}=\sigma_{i j} . S_{i j}
$$

The exit value $\mathrm{u}_{0}$ value after défuzzification is then:

$$
\mathrm{U}_{0}=\frac{\sum_{\mathrm{i}} \Sigma_{\mathrm{j}} \sigma_{\mathrm{ij}} \cdot \mathrm{s}_{\mathrm{ij}}}{\sum_{\mathrm{i}} \Sigma_{\mathrm{j}} \sigma_{\mathrm{ij}}}
$$

The calculation of $\mathrm{U}_{0}$, on all the field of excursion of $\mathrm{x}, \mathrm{y}$; gives the analytical model .

\subsection{Qualitative model:}

The qualitative model represented by the data of the two indices of collision risk in spaces right and left: allows choosing a movement of avoidance at the time of occurred of obstacles. This movement can be carried out in function of the model, in the form a linear velocity (advances) and an angle of rotation (orientation).Induced displacement must tend to a reduction in the greatest risk. The base of rules of the controller of the index of collision risk noted $\mathrm{C}$ is obtained to leave, from the analysis of the data sensors, and results from knowledge qualitative of the kinematics possibilities of the robot. They are given under form:

If $<<$ distance provided by sensor $1 \gg$ is $\mathrm{D}_{1}$, and ; $<$ distance provided by sensor $2>>$ is $D_{m}$ then $<<$ collision risk $>>$ is $C_{1 m}$

One notes this rule $\mathrm{R}_{\mathrm{lm}}$ and $\mathrm{C}_{\mathrm{lm}}$ linguistic variable characterizing the risk of collision associated at $R_{\operatorname{lm}}(1, \mathrm{~m} \in[1,4]) \cdot \mathrm{C}_{\mathrm{lm}}$ is the consequent one in the $\mathrm{R}_{\mathrm{lm}}$ rules . What gives us, the tables of the rules following form: 
Table (1): rule for index collision risk controller

\begin{tabular}{|c|c|c|c|c|c|}
\hline & \multicolumn{4}{|c|}{$d_{\mathbf{i}_{z}}$} \\
\hline & & TC & $c$ & L & TL \\
\hline \multirow{4}{*}{$\mathrm{d}_{\mathbf{i}_{1}}$} & TC & $\sigma_{11}$ & $C_{12}$ & $\sigma_{13}$ & $C_{14}$ \\
\hline & $c$ & $c_{21}$ & $\sigma_{22}$ & $C_{r 23}$ & $C_{24}$ \\
\hline & L & $C_{31}$ & $\sigma_{32}$ & $C_{33}$ & $C_{34}$ \\
\hline & TL & $\sigma_{41}$ & $\sigma_{42}$ & $C_{43}$ & $C_{44}$ \\
\hline
\end{tabular}

The base of rules of the controller of index of collision risk offers 16 different possibilities; who indicate the possible collision risk of the robot with its environment. The stability of the robot is reached for a symmetrical model, not in geometrical term, but with respect to the collision risk with the environment.

A module of orientation control consists of a fuzzy controller whose entries are the $\mathrm{Cg}, \mathrm{C}_{\mathrm{d}}$ components. of the qualitative model; and they will also be used as entry, for the linear speed controller.

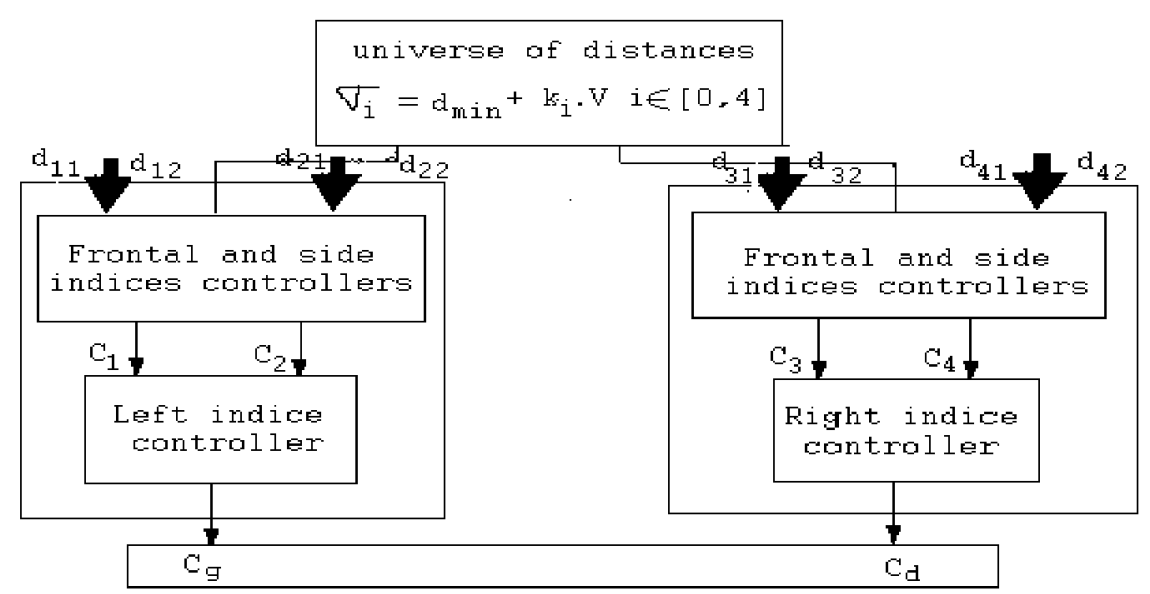

Figure (3): Algorithm of the qualitative model $\left(C_{g}, C_{d}\right)$

\section{SIMULATION:}

One take for the speed of the robot Vnom $=2 \mathrm{~ms}$; and an acceleration maximum of $1,5 \mathrm{~m} / \mathrm{s}^{2}$. One chose:

$\sigma 1=\sigma 4=1,0+2,5 . \lambda_{\mathrm{E}}$ Vnom

$\sigma 2=\sigma 3=1,5+3 . \lambda_{\mathrm{E}}$ Vnom 
The membership functions of the variable $\lambda_{E}$ are fuzzy singletons of which distribution is defined in a heuristic way: $\lambda_{E}=0$ corresponds to a space charged with obstacles $\left(C_{d}=0 ; C g=0\right)$ which causes the robot stop

$\lambda_{\mathrm{E}}=1$ corresponds to an open space $(\mathrm{Cd}=3 ; \mathrm{Cg}=3)$ which gives a maximum speed .

Figure (4) shows the results of the simulation of the behaviour of the robot in a corridor of $3 \mathrm{~m}$ wide where fixed obstacles of various dimensions, are placed Figure (5) represents the simulation of the behaviour in an Unknown environment together with another mobile obstacle. This example highlights the difficulties in characterizing the performances of a reactive system. Indeed a certain number of parameters intervene, like the rate of obstruction of space, relative configuration of the robot and the mobile obstacle; their respective speeds...

\section{Conclusion:}

As a whole the algorithm of simulation shows good performances for the qualitative model. There is however a case of failure for a singular situation, inherent to the model; however a solution to manage this situation would be to introduce a bias in orientation.

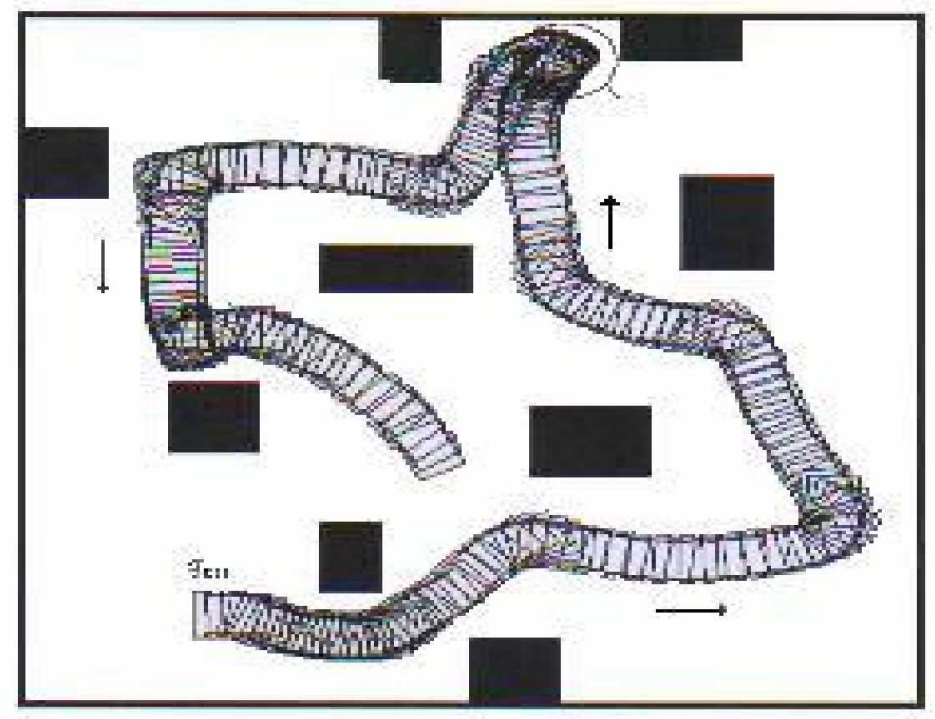

Figure (4): Avoidance of fixed obstacles 


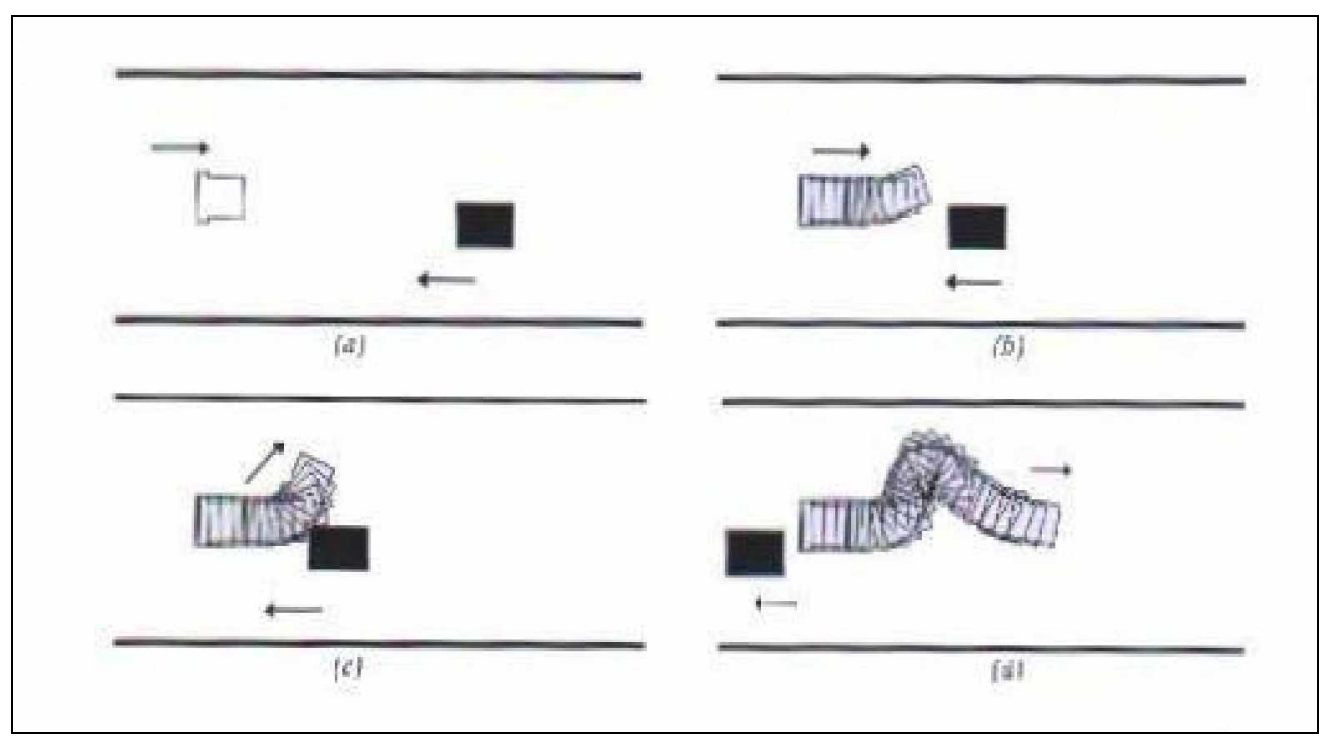

\section{References:}

Figure (5): Avoidance of mobile obstacle

[1] F. Baudouin, J.M. Favennec," Les capteurs intelligents, les concepts et les enjeux " Revue générale de l'électricité, mars 93 n³ pp1-8

[2] M. Bayart, "Instrumentation intelligente - Systèmes automatisés de production à Intelligence distribuée " Habilitation à diriger des recherches, Université de sciences et technologie de Lille; Décembre 1994

[3] B. Bouchon.Meunier, " La logique floue " presse universitaires de France Edition que sais-je ?1993

[4] G. Bourdon, Stratégie d'accostage entre robots mobiles autonomes constraints Approche par techniques floues; These de doctorat , L.R.Paris. 1994

[5] G. S. Blickley, Values join transmitter in getting smart, Control ingeneering January 1990 ; pp74-75 , January 1990

[6] L. Fouloy, J.F. Josserand, Fuzzy components network for intelligent Measurement and control, Submitted to the special issue of the I.E.E.E.transaction: Fuzzy systems on fuzzy components, Feb. 1995

[7] CIAME - AFCET Livre blanc : les capteurs intelligents, réflexion utilisateur, 1987

[8] M. ROBERT, M. Marchandieux, M.Porte, Capteurs intelligents Méthodologie d'évaluation, ed HERMES ,Paris 1993

[9] L. A. Zadeh, The calcul of fuzzy IF/THEN rules Al xpert, pp23-27 march 1992

[10] L.A. Zadeh, " The concept of a linguistic variable and its application to approxi-mate reasoning " information sciences, part 1 , vol 8.n 3 pp 199-249; part 2 vol ; $\mathrm{N}^{\circ} 8$ pp 301-357; part 3 vol n ${ }^{\circ}$ pp 43-80; 1975 